\title{
Поляризационно-селективная генерация в фотонно-кристаллической структуре с монослоем наночастиц
}

\author{
И.А. Глухов ${ }^{1, *}$, С.Г. Моисеев ${ }^{1,2}$, Ю.С. Дадоенкова ${ }^{1}$, И.О. Золотовский ${ }^{1}$ \\ ${ }^{1}$ Ульяновский государственный университет \\ ${ }^{2}$ Ульяновский филиал Института радиотехники и электроники им. В.А. Котельникова РАН \\ *E-mail: glukhov91@yandex.ru
}

DOI:10.31868/RFL2018.93-94

Применение фотонно-кристаллических структур (ФКС) с усиливающими компонентами открывает возможность создания компактных полупроводниковых лазеров с резонатором, работающим в оптическом и ближнем инфракрасном диапазонах. В то же время одним из основных препятствий для получения стабильной генерации в таком резонаторе может быть одновременное усиление волн с различными поляризациями, что приводит к возникновению крайне нежелательных поляризационных и амплитудных неустойчивостей, нарушающих стабильную работу лазера. Решением этой проблемы может быть использование тонкопленочного субволнового поляризатора, встроенного непосредственно в структуру ФКС. Данное решение позволит обеспечить компактность и минимизирует возможные оптические потери.

Настоящая работа посвящена изучению возможности использования тонкого полупроводникового слоя с включением металлических наночастиц сферической формы в качестве интегрированного поляризатора.

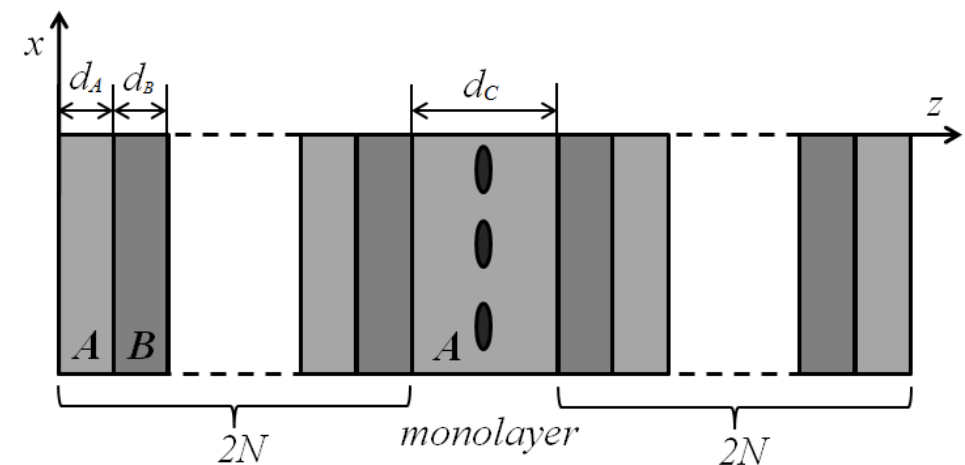

Рис. 1. Схема рассматриваемой структуры: два брегговских зеркала и композитный слой между ними. Композитный слой содержит монослой металлических наночастиц эллипсоидной формы.

Спектральные характеристики рассматриваемой резонаторной структуры рассчитываются при помощи матриц переноса. Рассматривается среда, имеющая $\mathrm{N}$ интерфейсов, под которыми понимаются как границы раздела объемных сред, так и монослой наночастиц. Интерфейсы ориентированы перпендикулярно оси z системы координат (рис. 1). Пространство между интерфейсами заполнено однородными изотропными средами с диэлектрическими проницаемостями $\varepsilon_{A}=12,25-0,007 i$ и $\varepsilon_{B}=11,56-0,007 i$. Композитный слой выполнен на основе диэлектрика с диэлектрической проницаемостью $\varepsilon_{C}=\varepsilon_{A}$ и имеет толщину $d_{C}=2 d_{A}$. Толщины слоев $d_{A}$ и $d_{B}$ обеспечивают выполнение условия брэгговской дифракции на длине волны $\approx 1,75$ мкм, при этом коротковолновый 
край фотонной запрещенной зоны (ФЗ3) всей ФКС приходится на длину волны 1,55 мкм.

На слоистую структуру в направлении оси $z$ падает плоская монохроматическая волна, которая вследствие переотражений на интерфейсах создает встречные волны во всех слоях структуры. В рамках теории матриц переноса спектральные характеристики ФКС определяются матрицей переноса $\hat{G}_{x, y}=\hat{F}_{1} \hat{F}_{2} \hat{F}_{3} \cdots \hat{F}_{x, y} \cdots \hat{F}_{N}$, сформированной перемножением матрицы переноса через монослой наночастиц $\hat{F}_{x, y}=\left[[1,0],\left[-2 \varepsilon_{c} r_{x, y} / t_{x, y}, 1\right]\right]$ и матриц переноса через диэлектрические слои $\quad \hat{F}_{j}=\left[\left[\cos \delta_{j},-i \varepsilon_{j}^{-1 / 2} \sin \delta_{j}\right],\left[-i \varepsilon_{j}^{1 / 2} \sin \delta_{j}, \cos \delta_{j}\right]\right], \quad$ где $\delta_{j}=k_{0} \varepsilon_{j}^{1 / 2} d_{j}-$ фазовые толщины слоев. Наночастицы монослоя имеют сфероидную форму, ориентированы в его плоскости в одном направлении, что приводит к существенной зависимости амплитудных коэффициентов отражения $\left(r_{x, y}\right)$ и пропускания $\left(t_{x, y}\right)$ от поляризации световой волны вблизи локализованных поверхностных плазмонных резонансов наночастиц.

На рис. 2 приведен спектр пропускания ФКС в условиях, когда световой вектор падающей волны ориентирован поперек (штриховая линия) или вдоль (сплошная линия) направления ориентации сфероидных частиц. Для продольной поляризации возбуждается локализованный поверхностный плазмонный резонанс наночастиц, приходящийся на длину волны 1,55 мкм, что приводит к подавлению генерации ФКС в данной области спектра. Для поперечной поляризации плазмонный резонанс наночастиц возбуждается вдали от ФЗ3 слоистой структуры, что позволяет реализовать генерацию на длине волны 1,55 мкм. Полученный эффект может быть использован для поляризационного управления лазерным излучением.

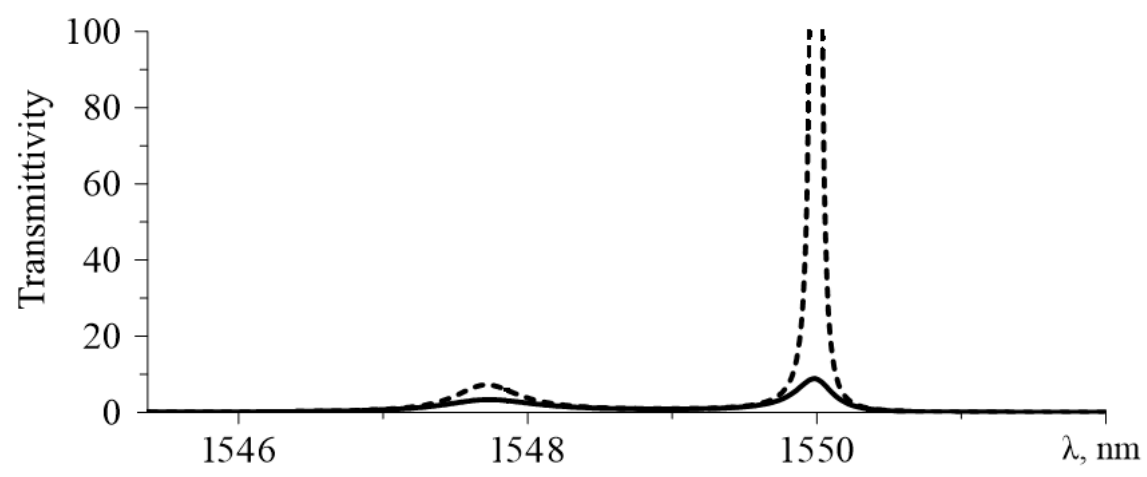

Рис. 2. Спектры пропускания в области фотонной запрещенной зоны усиливающего ФКС с монослоем наночастиц для поляризации вдоль (сплошная линия) и перпендикулярно (штриховая линия) направлению ориентации полярной оси наночастиц.

Работа выполнена при финансовой поддержке Министерства образования и науки РФ (проекты 3.5698.2017/9.10, 3.8388.2017/ИТР), Российского научного фонда (проект 18-12-00457) и Российского фонда фундаментальных исследований (проекты 17-02-01382, 18-42-730007). 